\title{
BMJ Global Health Effect of micronutrient supplements on influenza and other respiratory tract infections among adults: a systematic review and meta-analysis
}

\author{
Ajibola Ibraheem Abioye (D) , ${ }^{1}$ Sabri Bromage, ${ }^{1}$ Wafaie Fawzi ${ }^{2}$
}

To cite: Abioye Al, Bromage S, Fawzi W. Effect of micronutrient supplements on influenza and other respiratory tract infections among adults: a systematic review and metaanalysis. BMJ Global Health 2021;6:e003176. doi:10.1136/ bmjgh-2020-003176

Handling editor Seye Abimbola

- Additional material is published online only. To view, please visit the journal online (http://dx.doi.org/10.1136/ bmjgh-2020-003176).

Received 16 June 2020 Revised 30 November 2020 Accepted 11 December 2020

\section{SLinked}

- http://dx.doi.org/10.1136/ bmjgh-2020-004896

Check for updates

(C) Author(s) (or their employer(s)) 2021. Re-use permitted under CC BY-NC. No commercial re-use. See rights and permissions. Published by BMJ.

${ }^{1}$ Department of Nutrition, Harvard University T H Chan School of Public Health, Boston, Massachusetts, USA

${ }^{2}$ Department of Global Health and Population, Harvard T H Chan School of Public Health, Boston, Massachusetts, USA

Correspondence to Dr Ajibola Ibraheem Abioye; iaa551@g.harvard.edu

\section{ABSTRACT}

Acute respiratory tract infections (ARIs) are a leading cause of ill-health and death globally. Individual or multiple micronutrients have been shown to modulate immune function and affect the risk and severity of a number of infectious diseases. We systematically reviewed the evidence on the impact of micronutrient supplements to reduce the occurrence of ARIs and shorten the duration of ARI symptoms among adults. Random effects metaanalyses were conducted to estimate the pooled effects of vitamin D, vitamin C, zinc and multiple micronutrient supplementation (MMS) on the occurrence of ARIs and the duration of $A R I$ symptoms. Vitamin $D$ supplementation reduced the risk of $A R I$ (risk ratio (RR) $=0.97 ; 95 \% \mathrm{Cl}$ 0.94 to $1.00 ; p=0.028)$ and shortened the duration of symptoms (per cent difference: $-6 \%(95 \% \mathrm{Cl}-9 \%$ to $-2 \% ; p=0.003))$. The RR of vitamin $D$ to prevent ARI was farther from the null when diagnosis was based on clinical diagnosis or laboratory testing, compared with self-report and when the loading dose was $<60000$ IU. Vitamin C supplementation reduced the risk of ARIs ( $R R=0.96 ; 95 \%$ $\mathrm{Cl} 0.93$ to $0.99 ; \mathrm{p}=0.01$ ) and shortened the duration of symptoms (per cent difference: $-9 \%(95 \% \mathrm{Cl}-16 \%$ to $-2 \% ; p=0.014)$ ). The effect of vitamin $C$ on preventing ARI was stronger among men and in middle-income countries, compared with women and high-income countries, respectively. Zinc supplementation did not reduce the risk of ARIs but shortened the duration of symptoms substantially (per cent difference: $-47 \%(95 \% \mathrm{Cl}-73 \%$ to $-21 \% ; p=0.0004))$. Our synthesis of global evidence from randomised controlled trials indicates that micronutrient supplements including zinc, vitamins $C$ and $D$, and multiple micronutrient supplements may be modestly effective in preventing ARIs and improving their clinical course. Further research is warranted to better understand the effectiveness that individual or multiple micronutrients have on SARS-CoV-2 infection and treatment outcomes.

\section{INTRODUCTION}

Acute respiratory tract infections (ARIs) constitute a substantial global burden of disease. ARIs were the third leading cause of death globally in 2017. ${ }^{1}$ ARIs are caused by bacteria and viruses-and a large proportion

\section{Key questions}

\section{What is already known?}

- Vitamin C and D supplementation reduce the risk of acute respiratory tract infections (ARIs).

- Vitamin C and zinc supplementation shorten the duration of ARI symptoms.

What are the new findings?

- The preventive effect of vitamin D against ARls is greater when the diagnosis is based on clinical diagnosis or laboratory testing, rather than self-report. An optimal dosing regimen would include a daily dose $\geq 2000$ IU vitamin D and a loading dose $<60$ $000 \mathrm{IU}$.

- Vitamin D supplementation shortens the duration of ARI symptoms mildly, though the effect did not differ by dose.

- The preventive effect of vitamin C against ARls is greater among men and residents of middle-income countries.

- Zinc supplementation has no effect on the risk of ARIs.

What do the new findings imply?

- Micronutrient supplementation may prevent (vitamin D and C) and treat (vitamin D, C and zinc) for ARIs, including SARS-CoV-2 infection. It is unclear whether the magnitude of the effects of these micronutrients are clinically meaningful.

- The efficacy and safety of micronutrients, provided at the dose ranges at which their effects are strongest, need to be tested in randomised trials among patients with COVID-19 and other severe respiratory infections.

of cases are due to RNA viruses. Every year, seasonal influenza epidemics affect 3-5 million cases and result in $>300000$ deaths globally. ${ }^{2}$ SARS-CoV-2, a novel enveloped non-segmented RNA virus, is the cause of the ongoing COVID-19 pandemic. ${ }^{3}$ Between December 2019 and November 2020, there have been more than 60 million confirmed cases of COVID-19 and almost 1.5 million 
deaths. There is currently no known curative therapy for the disease.

Early reports suggest that severe COVID-19 disease and deaths have been more frequent among older adults, with lower risk and severity among children. ${ }^{45}$ Understanding the influence of nutrition in preventing and treating ARIs could guide the design of public health programmes. Previous studies have demonstrated the association of nutrient depletion and the risk of infectious diseases. ${ }^{6}$ A number of reviews have summarised findings from randomised trials of vitamin $\mathrm{D},^{7-11}$ vitamin $\mathrm{C}^{12-14}$ and zinc $^{15-18}$ to prevent and treat ARIs. These reviews were not focused on adults, and did not carefully consider the influence of dose or comprehensively consider the effect of multiple micronutrients towards identifying a suitable micronutrient package to prevent or treat ARIs.

The goal of this paper is to synthesise the evidence from randomised controlled trials (RCTs) of micronutrient supplementation to prevent and treat ARIs in adults. We evaluated the effectiveness of micronutrient supplements in (1) Preventing ARIs, and (2) Reducing the duration of ARI symptoms.

\section{METHODS}

\section{Systematic literature search and selection of studies}

We searched the medical literature databases, Medline and EMBASE, for original research articles published as of March 2020. Medical subject headings and keywords representing micronutrients (vitamins $\mathrm{A}, \mathrm{B}, \mathrm{C}, \mathrm{D}, \mathrm{E}$ or zinc) and ARIs were employed (online supplemental table 1). No restrictions were made in the search based on pathogen, age, year or language of publication (however, articles for which there was no standard translation were excluded during full-text review). We also searched through the reference lists of included papers and published systematic reviews by hand. The titles and abstracts of identified studies were screened, and full texts were examined. Influenza, caused by enveloped RNA viruses, Influenzavirus $A$ and $B,{ }^{19}$ was the main ARI of interest. We included RCTs that examined the influence of micronutrient supplementation on the occurrence of any ARIs or duration of symptoms. In vitro studies, case studies, case series and observational studies (prospective and retrospective) were excluded. Studies were also excluded if they included only individuals aged $<18$ years or if the mean age of included participants was $<18$ years.

Data on study design, population characteristics, exposures, outcomes, covariates and findings were abstracted from the included studies, including point estimates with CIs, SEs and $p$ values. These include means, medians and mean difference for continuous outcomes and risk ratios (RRs), ORs and HRs for categorical outcomes. The $\mathrm{SD}$ was assumed to be equal to the mean if the studies did not report any measures of uncertainty. For studies that reported summary data for exposed and unexposed participants, RRs and HRs were estimated as appropriate using the epiR package in $\mathrm{R}^{20}$ Additional information on the prevalence of baseline $25(\mathrm{OH}) \mathrm{D}$ concentration $<25 \mathrm{nmol} / \mathrm{L}$ was extracted from a published pooled individual patient data meta-analysis. ${ }^{10}$

Risk of bias was assessed using the Cochrane Collaboration's revised tool for assessing risk of bias in randomised trials. ${ }^{21}$ No inclusion or analysis decisions were made based on risk of bias.

\section{Meta-analysis}

We pooled estimates for exposure-outcome relationships reported by four or more studies. If different approaches were used to measure the outcome, the more objective or precise outcome measure was preferred. Thus, for studies reporting on the occurrence of infection, RT-PCR and serology were preferred to clinical diagnosis, and self-report by patients was the least preferred diagnosis approach. If multiple doses of exposure were reported, the most extreme categories meeting the criteria for inclusion were included in the meta-analysis.

Random effects meta-analysis based on the maximum likelihood was conducted. The random effects approach was selected a priori because it accounts for variability in the true intervention effect. Pooled risk ratios (RR) were obtained for the occurrence of infection and percentage differences were obtained for the duration of symptoms. Percentage difference was estimated as the logtransformed ratio of the mean duration of symptoms in the treatment and control arms. ${ }^{22}$ Percentage difference was preferred to the weighted and standardised mean difference measures because, it is easily interpretable, and it accounts for differences in estimating the duration of symptoms. ${ }^{23} 24$

Heterogeneity was assessed with Higgins' $\mathrm{I}^{2}$ statistic, a measure of the total variability due to between-study variation. $\mathrm{I}^{2}$ was regarded as substantial if $50 \%-90 \%$ and considerable if $>90 \% .{ }^{25}$ Heterogeneity was further assessed using meta-regression approaches and analysis within subgroups defined by country-income classification, age, diagnostic method, and loading and maintenance doses. The effect of micronutrient supplements in subgroups defined by the type of ARI (such as common cold) was examined where possible. Dose-response analysis was done using a single predictor and multiple meta-regression. Alternative models for multiple metaregression were considered and the best model was the model with the lowest Akaike information criterion. In some cases, sensitivity analyses were conducted, by altering the parameters of inclusion in the main analyses and comparing findings. Publication bias was evaluated with visual inspection of funnel plots. Double-sided $p$ values were estimated, and significance was set at $\mathrm{p}<0.05$. Meta-analyses were conducted using the Metafor package $^{26}$ in RStudio V.1.0.153. ${ }^{27}$

\section{RESULTS}

We identified 80 RCTs (figure 1 ) that examined the effect of micronutrient supplements on the risk and clinical 


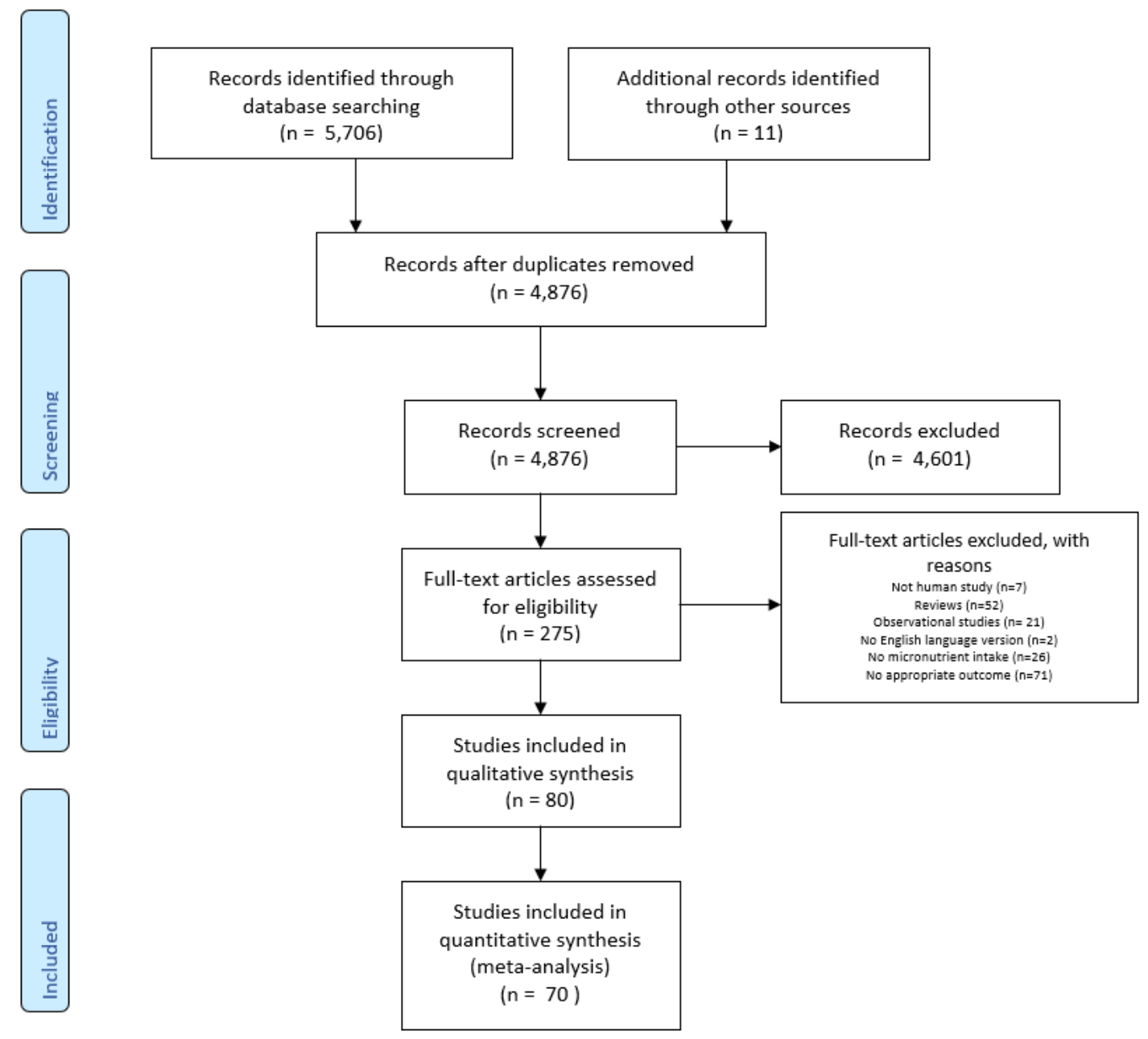

Figure 1 Flow chart of selected studies.

course of ARIs. These studies enrolled individuals across 17 high-income countries, and 5 low-income and middleincome countries. Meta-analyses of the effect of micronutrients on the risk of ARI and duration of symptoms were done when possible (tables 1-3). Risk of bias for all studies is presented in online supplemental table 2 and summarised in each section below.

\section{Vitamin D supplementation}

Occurrence of illness

Twenty studies examined the effect of vitamin D supplementation on ARI risk among 9902 adults (online supplemental table 3). These studies were conducted in Australia, ${ }^{28}$ Canada, ${ }^{29}$ Finland, ${ }^{30}$ Japan, ${ }^{31} 32$ the Netherlands, ${ }^{33}$ New Zealand, ${ }^{34-36}$ Sweden, ${ }^{37}$ the $\mathrm{UK}^{38-40}$ the USA. ${ }^{41-47}$ The studies provided daily doses alone, ${ }^{30} 313746$ daily doses after a single loading or monthly dose, ${ }^{32} 43$ or large single, weekly or monthly doses only. ${ }^{28} 29343538-404447$ Doses used were $400 \mathrm{IU}^{30}, 3^{32} 1000 \mathrm{IU}^{33},{ }^{46} 2000 \mathrm{IU}^{4142}$ or $4000 \mathrm{IU}^{3743}$ daily; $10000 \mathrm{IU}^{29}$ weekly; or $60000 \mathrm{IU}^{47}$ or $200000 \mathrm{IU}^{3444}$ monthly. The durations of the trials varied from 6 weeks to 3 years. There was a low risk of bias in three trials, ${ }^{282934}$ with some concerns in nine trials ${ }^{313235364043-4547}$ and a high risk of bias in eight studies. ${ }^{30} 37-39414246$
Vitamin D reduced ARI risk by $69 \%$ after 3 years of follow-up among 208 postmenopausal African-American women ${ }^{42}$ whose participation was not dependent on their baseline serum 25(OH)D level, but had no effect among a separate group of 260 African-American women when serum $25(\mathrm{OH}) \mathrm{D}$ level was maintained at $\geq 30 \mu \mathrm{g} / \mathrm{L}$. ${ }^{41}$ Three other studies found a significant effect of vitamin D supplementation..$^{29} 374$ These were conducted among 107 US nursing home residents, ${ }^{44} 124$ Swedish adults with a high burden of $\mathrm{ARI}^{37}$ and 600 university students in Canada. ${ }^{29}$

Four studies in the Netherlands, ${ }^{33}$ Finland $^{30}$ and the $\mathrm{USA}^{4346}$ examined the influence of vitamin D supplementation to prevent common cold, and none found significant effects. ${ }^{30} 334346$ One study among 223 patients with inflammatory bowel disease in Japan found no significant effect of vitamin $\mathrm{D}$ on preventing influenza. ${ }^{31}$ The overall risk of upper respiratory tract infection (URTI), however, decreased by $41 \%$ (95\% CI $2 \%$ to $65 \%$ ). One study among 322 adults in New Zealand found no effect of vitamin D supplementation on preventing URTIs caused by adenovirus, coronaviruses, influenza viruses, rhinovirus, respiratory syncytial 
BMJ Global Health

Table 1 Vitamin D-summary of meta-analyses findings - main and subgroups

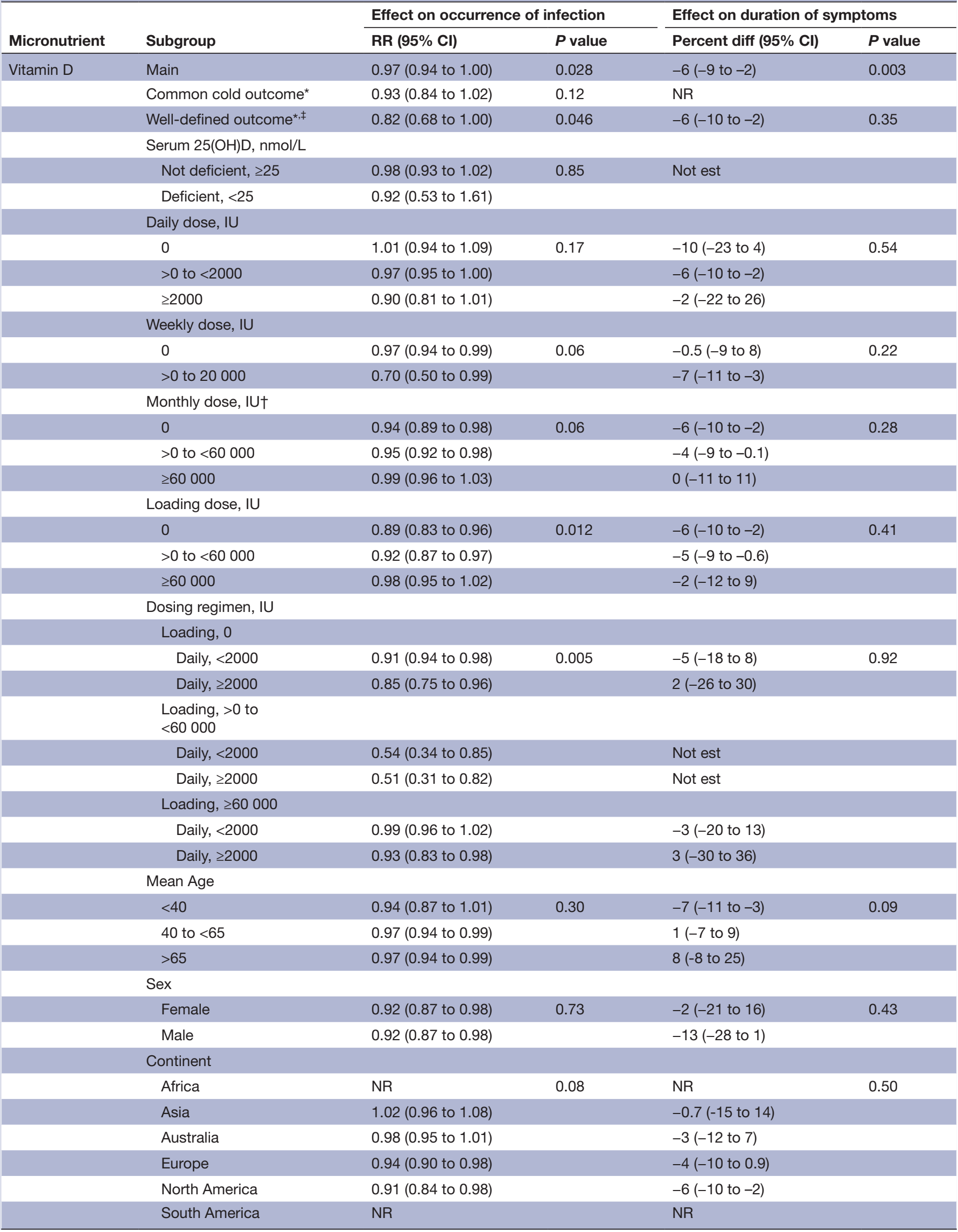

Continued 


\begin{tabular}{|c|c|c|c|c|c|}
\hline \multirow[b]{2}{*}{ Micronutrient } & \multirow[b]{2}{*}{ Subgroup } & \multicolumn{2}{|c|}{ Effect on occurrence of infection } & \multicolumn{2}{|c|}{ Effect on duration of symptoms } \\
\hline & & RR $(95 \% \mathrm{Cl})$ & $P$ value & Percent diff (95\% Cl) & $P$ value \\
\hline & \multicolumn{5}{|l|}{ Length of trial } \\
\hline & $<2$ weeks & NR & 0.08 & NR & 0.12 \\
\hline & 2 weeks to $<3$ months & 0.93 (0.88 to 0.98$)$ & & $-7(-11$ to -3$)$ & \\
\hline & 3 months to $<1$ year & 0.94 (0.90 to 0.98$)$ & & $-5(-9$ to -0.5$)$ & \\
\hline & $>1$ year & 0.96 (0.94 to 0.99$)$ & & $2(-9$ to 12$)$ & \\
\hline
\end{tabular}

NR: Not relevant; that is, no primary studies that met the criteria. All studies were conducted in high-income countries.

Not est: Not estimated; that is meta-analysis was not done.

*Sensitivity analysis.

†Includes studies that provided 2 monthly doses, categorised in monthly equivalents.

‡Outcome was defined based on clinical diagnosis and laboratory testing. Cases based on self-report were excluded.

virus and parainfluenza viruses, diagnosed based on RT-PCR. ${ }^{34}$

Other studies found no significant impact of vitamin $\mathrm{D}$ on the risk of ARI. These were conducted among community-dwelling adults by age or health status, ${ }^{28} 45$ older adults and their carergivers, ${ }^{38}$ patients with chronic obstructive pulmonary disease ${ }^{39}$ or asthma, ${ }^{40}$ or patients with a previous colorectal adenoma. ${ }^{46}$

The pooled RR of the impact of supplementation on ARI occurrence from 20 studies $^{28-47}$ was $0.97(95 \%$ CI 0.94 to $1.00 ; \mathrm{p}=0.028$, figure 2$)$. There was no significant heterogeneity $\left(\mathrm{I}^{2}=4 \%\right)$, and no evidence of publication bias on inspection of the funnel plot (online supplemental figure 1). None of the individual studies had significant influence on the pooled estimate. Among four studies reporting on vitamin D and common cold prevention, ${ }^{30} 334346$ the pooled RR of the effect was 0.93 (0.84 to 1.02; $\mathrm{p}=0.12$; online supplemental figure 2). There was no heterogeneity in the estimates $\left(\mathrm{I}^{2}=0 \%\right)$. The funnel plot was asymmetrical, (online supplemental figure 3), suggesting possible publication bias. Trim-andfill analysis suggests eight studies may be missing on the right side, and the corrected pooled RR would be 0.98 (0.96 to 1.01$)$.

The pooled RR of ARI was 0.82 (95\% CI 0.68 to 1.00 ; $\mathrm{p}=0.046$ ) among six studies 282931353744 whose outcomes were based on clinical diagnosis or laboratory testing (that is, excluding self-report (table 1)). The pooled RR of ARI was statistically significant when monthly or loading dose $<60000$ IU, but not when $\geq 60000$ IU. Weekly doses were also statistically significant. Using multiple meta-regressions, we identified an optimal dosing regimen from alternatives with different magnitudes of daily, weekly, monthly or loading doses. The best regimen included daily vitamin $\mathrm{D} \geq 2000$ IU following a loading dose $<60000 \mathrm{IU}$.

\section{Duration of symptoms}

Six studies reported on the effect of vitamin D on the duration of symptoms due to ARI ${ }^{29} 3234353845$ among 1400 adults. There was a low risk of bias for two studies, ${ }^{29} 34$ with some concerns for three studies ${ }^{32} 3545$ and high for one study. ${ }^{38}$ Only one of these, a Canadian study, reported that vitamin D shortened the duration of symptoms-from 6.2 to 5.8 days. ${ }^{29}$ Vitamin D had no impact on the duration of symptoms among community-dwelling adults in the $\mathrm{USA}^{45}$ and New Zealand, ${ }^{29}$ older UK adults and their carers, ${ }^{38}$ and among patients admitted for pneumonia in New Zealand. ${ }^{35}$ The pooled per cent difference in duration was $-6 \%$ (95\% CI $-9 \%$ to $-2 \%$; $\mathrm{p}=0.003$, figure 3$)$. There was no significant heterogeneity $\left(\mathrm{I}^{2}=7 \%\right)$, and no evidence of publication bias on inspection of the funnel plot. The one study with a significant effect ${ }^{29} \mathrm{had}$ substantial influence on the pooled estimate; if this study were left out of the analysis, the pooled percentage difference would be $-0.5 \%$ (95\% CI $-9.4 \%$ to $8.5 \%, \mathrm{p}=0.92)$. Heterogeneity was not influenced by the magnitude of the daily dose $(\mathrm{p}=0.51)$, weekly dose $(\mathrm{p}=0.22)$, monthly dose $(\mathrm{p}=0.28)$ or the loading dose $(\mathrm{p}=0.54)$.

\section{Vitamin C supplementation}

\section{Occurrence of illness}

Twenty-four studies examined the effect of vitamin $\mathrm{C}$ on the risk of common cold among 10961 adults (online supplemental table 4). The risk of bias was with some concerns for 19 studies ${ }^{48-66}$ or high for 5 studies. ${ }^{67-71}$ These studies were conducted in Australia, ${ }^{484972}$ Canada, ${ }^{50516673}$ Japan, ${ }^{52}$ South Africa, ${ }^{53-55}$ Sweden, ${ }^{56}$ the $\mathrm{UK}^{57-60} 67$ 74-76 and the USA. ${ }^{61-65} 68-7177$ The studies provided daily doses alone $^{48} 4951-54575963-67697075$ or daily doses with loading doses. The daily doses were $<250 \mathrm{mg},{ }^{56} 6970250 \mathrm{mg}$ to $<1000 \mathrm{mg},{ }^{52-55} 1000 \mathrm{mg}^{4849} 5157596264-6775$ or $2000 \mathrm{mg}^{63}$ The loading doses were $300 \mathrm{mg}^{56}$ or $3000 \mathrm{mg} .{ }^{62}$ One study provided a range of daily ( $250 \mathrm{mg}$ to $2000 \mathrm{mg}$ ) and loading doses (4000 $\mathrm{mg}$ to $8000 \mathrm{mg}){ }^{50}$

Fourteen studies of vitamin $\mathrm{C}$ and common cold risk reported significant protective effects. Vitamin C was protective against common cold by $49 \%$ among 90 staff and students of a university in the UK, by $57 \%$ among 112 soldiers in Canada and by $45 \%$ among 28 men with marginal vitamin $\mathrm{C}$ status in the USA ${ }^{65}$ Among 305 individuals in a village with high gastric cancer mortality in Japan, $500 \mathrm{mg}$ /day of vitamin C led to $64 \%$ lower risk of common cold over 5 years. ${ }^{52}$

Vitamin $\mathrm{C}$ had no significant effect on the risk of common cold in 10 other studies conducted in 
Table 2 Vitamin C-summary of meta-analyses findings-main and subgroups

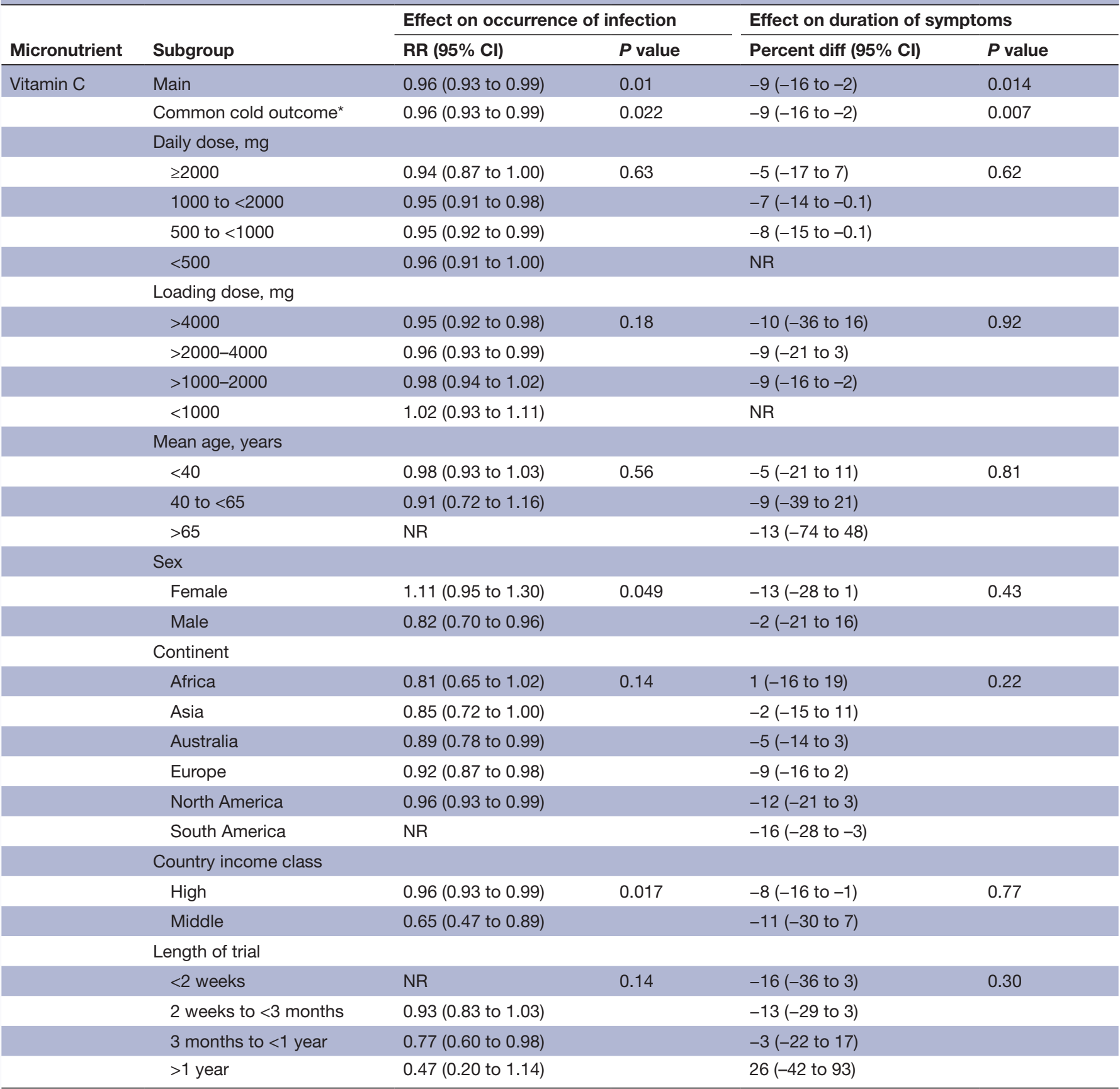

NR: Not relevant; that is, no primary studies that met the criteria.

*Sensitivity analysis.

Australia, ${ }^{4849}$ Canada, ${ }^{5166}$ the $\mathrm{UK}^{59}{ }^{70}$ and the USA. ${ }^{62636978}$ Four of these studies had sample sizes $>500^{51596370}$ and six had smaller sample sizes. ${ }^{484962666975}$ Two of these studies were among military men or cadets in training. ${ }^{63} 66$ Four studies among marathoners in the USA $(n=92)$ and South Africa $(n=32)$, or among marathoners age-matched with non-runners $(n=340 \text { and } n=167)^{53}$ found no effect of vitamin $\mathrm{C}$ on preventing ARIs.

The pooled RR of vitamin $\mathrm{C}$ on preventing ARI (common cold and non-specific ARIs) was 0.96 (95\% CI 0.93 to $0.99 ; \mathrm{p}=0.01$; figure 4 ). There was no evidence of heterogeneity $\left(\mathrm{I}^{2}=0 \%\right)$, though asymmetry in the funnel plot suggests possible publication bias with fewer studies with estimates below the pooled RR than above it (online supplemental figure 5). Trim-and-fill analysis suggests five studies may be missing on the right side, though the pooled RR and CIs do not change.

Omitting one study ${ }^{51}$ with an RR of 0.91 (95\% CI 95\% CI 0.85 to 0.98$)$ in influence analysis changed the pooled RR to 0.98 (95\% CI 0.94 to 1.01$)$. I ${ }^{2}$ did not change. The pooled RR significantly differed by sex $(\mathrm{p}=0.049)$. The pooled RR was 1.11 (95\% CI 0.95 to 1.30$)$ and 0.82 (95\% CI 0.70 to 0.96 ) in women and men, respectively. The pooled RR significantly differed by country income 
Table 3 Zinc-summary of meta-analyses findings-main and subgroups

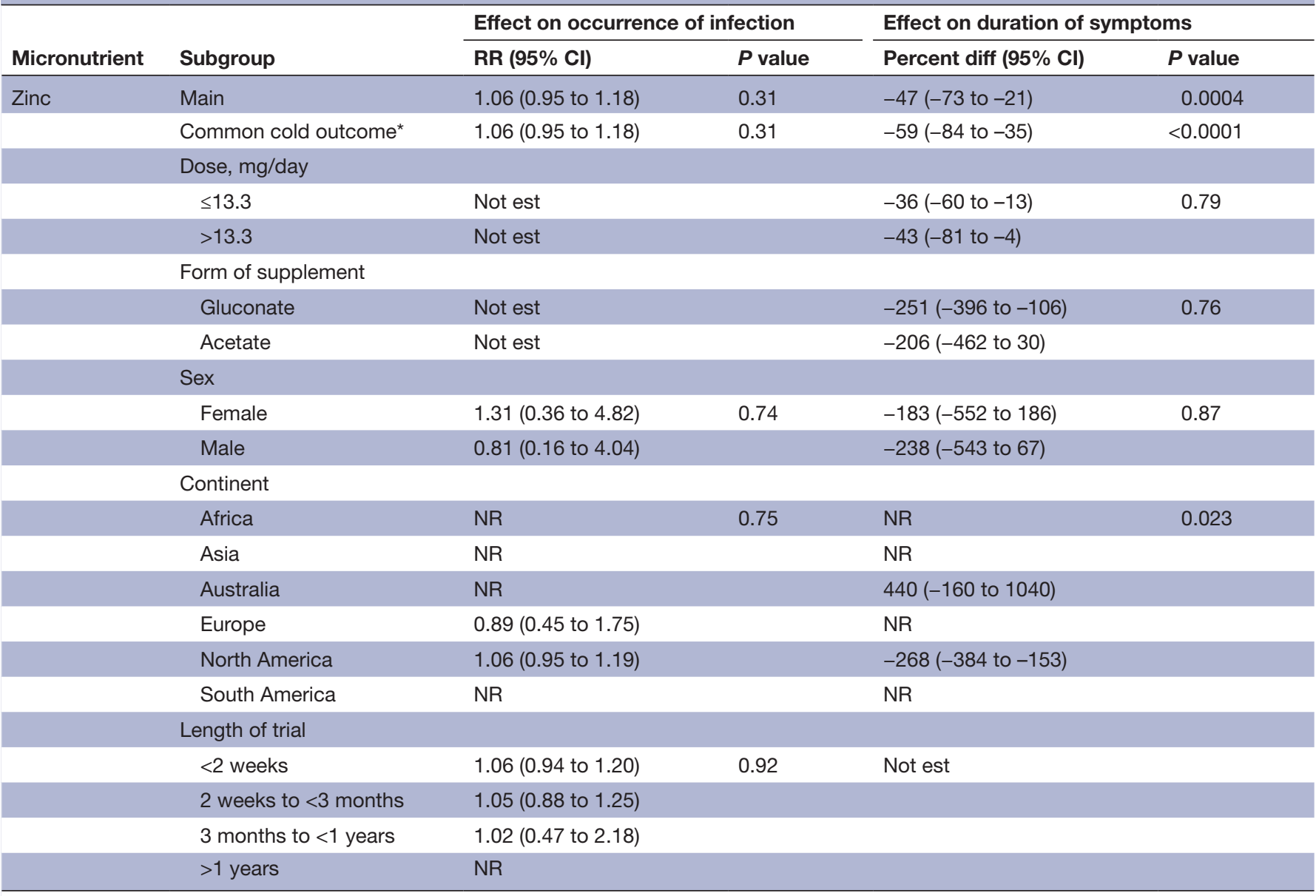

NR: Not relevant; that is, no primary studies that met the criteria. The mean age for all included studies was $<40$ years.

Not est: Not estimated; that is meta-analysis was not done.

*Sensitivity analysis.

classification $(\mathrm{p}=0.017)$. The pooled RR was $0.65(95 \% \mathrm{CI}$ 0.47 to 0.89$)$ in middle-income countries and $0.96(95 \%$ CI 0.93 to 0.99 ) in high-income countries. The pooled
RR was neither influenced by the magnitude of the daily dose $(p=0.63)$ nor the loading dose $(p=0.18)$. The pooled RR was not significantly influenced by mean age,

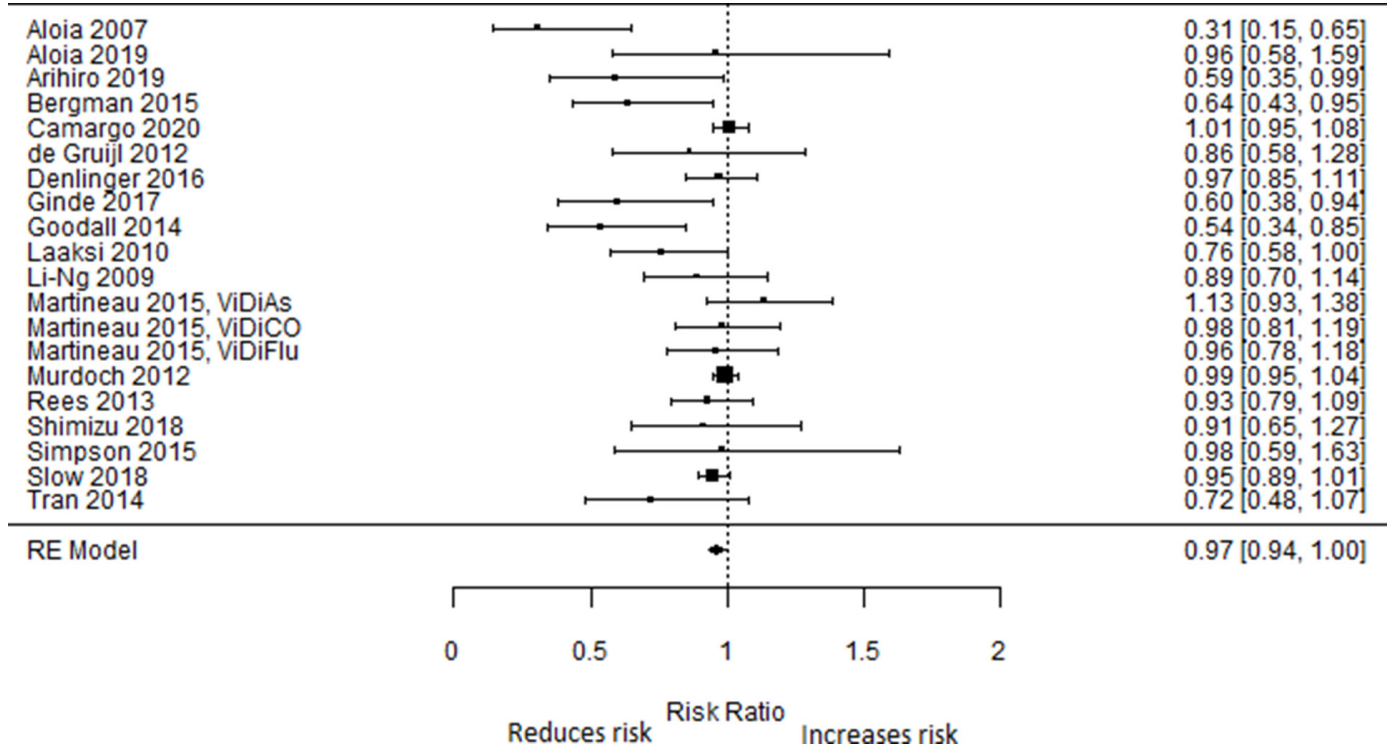

Figure 2 Vitamin D to reduce the risk of acute respiratory tract infection (ARI) among adults. RE, Random effects. 


\begin{tabular}{|c|c|c|c|c|}
\hline \multicolumn{2}{|l|}{ Goodall 2014} & $\square$ & & $-0.07[-0.11,-0.03]$ \\
\hline \multicolumn{2}{|l|}{ Li-Ng 2009} & 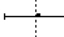 & & $0.02[-0.22,0.26]$ \\
\hline \multicolumn{2}{|c|}{ Martineau 2015, ViDiFlu } & 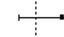 & & $0.18[-0.13,0.49]$ \\
\hline \multicolumn{2}{|c|}{ Murdoch 2012} & $\mapsto$ & & $0.00[-0.11,0.11]$ \\
\hline \multicolumn{2}{|l|}{ Shimizu 2018} & $\longrightarrow$ & & $-0.26[-0.69,0.16]$ \\
\hline \multicolumn{2}{|l|}{ Slow 2018} & $\longrightarrow$ & & $-0.23[-0.64,0.17]$ \\
\hline \multirow[t]{2}{*}{ RE Model } & & * & & $-0.06[-0.09,-0.02]$ \\
\hline & 1 & : & $T$ & $\neg$ \\
\hline \multirow[t]{3}{*}{-2} & -1 & 0 & 1 & 2 \\
\hline & \multicolumn{3}{|c|}{ Log Ratio of Means } & \\
\hline & luce & & reas & tion \\
\hline
\end{tabular}

Figure 3 Vitamin D to shorten the duration of symptoms of acute respiratory tract infection (ARI). RE, Random effects.

but none of the included studies were restricted to older adults (mean age of participants $>60$ years). The pooled RR was also not significantly influenced by mean age or duration of the trial.

The pooled RR of the effect of vitamin $\mathrm{C}$ on prevention of common cold was 0.96 (95\% CI 0.93 to 0.99 ; $p=0.022$; online supplemental figure 6 ). There was no heterogeneity in the estimates $\left(\mathrm{I}^{2}=0 \%\right)$. The funnel plot was asymmetrical, (online supplemental figure 7), suggesting possible publication bias. Trim-and-fill analysis suggests one study may be missing on the right side, and the corrected pooled RR does not change.

\section{Duration of symptoms}

Twenty-four studies evaluated the influence of vitamin $\mathrm{C}$ on the duration of common cold symptoms among 8344 adults. Study outcome was based on self-report, and the risk of bias of all studies was with 'some concerns'. These studies were conducted in Australia, 484972 Brazil, Canada, ${ }^{50516673}$ Japan, ${ }^{52}$ South Africa, ${ }^{53-55}$ the $\mathrm{UK}^{58-60677576}$ and the USA. ${ }^{61} 63-657879$ Included studies provided daily doses ranging from $0 \mathrm{mg}$ to $3000 \mathrm{mg}$, with or without loading doses from $1500 \mathrm{mg}$ to $8000 \mathrm{mg}$. Seven of these found that vitamin $\mathrm{C}$ shortened the duration of symptoms significantly. ${ }^{496167757980}$ In one study, vitamin C shortened the duration of symptoms in men but not in women. ${ }^{60}$ In another study, vitamin $\mathrm{C}$ increased the duration of symptoms in women but had no effect in men. ${ }^{76}$ The other 11 studies $^{4850-525859636566727378 \text { found no significant effect }}$ of vitamin $\mathrm{C}$ on the duration of symptoms.

One study evaluated the proportion of participants who experienced symptom relief by the fourth and seventh days of supplementation among families in the UK randomised to $1000 \mathrm{mg}$ /day of vitamin C compared with placebo. ${ }^{74}$ Vitamin $\mathrm{C}$ had no effect on whether symptoms were relieved by the fourth or seventh days.

In addition to the studies of common cold above, two studies evaluated the effect of vitamin C on the duration of URTIs among marathoners in South Africa and the USA, matched with non-runners. While vitamin $\mathrm{C}$ shortened the duration of URTI symptoms among marathoners and increased the duration in sedentary non-marathoners in the US study, vitamin C shortened the duration of URTI in non-marathoners in the South African study but had no effect on marathoners. ${ }^{53}$

Figure 5 presents the pooled percentage difference of the effect of vitamin $\mathrm{C}$ on the duration of ARI symptoms. Vitamin $\mathrm{C}$ shortened the duration of ARI symptoms by $9 \%(95 \%$ CI $2 \%$ to $16 \% ; \mathrm{p}=0.014)$. There was substantial heterogeneity in the estimates $\left(\mathrm{I}^{2}=72 \%\right)$ and no evidence of publication bias on inspection of the funnel plots (online supplemental figure 8). None of the individual studies had significant influence on the magnitude or direction of the pooled estimates. The pooled percentage difference was neither influenced by the magnitude of daily dose $(p=0.63)$ nor loading dose $(p=0.92)$. None of the included studies was restricted to the older population, or had a participants' mean age $>65$ years.

The pooled percentage difference of the effect of vitamin C (online supplemental figure 9) on shortening

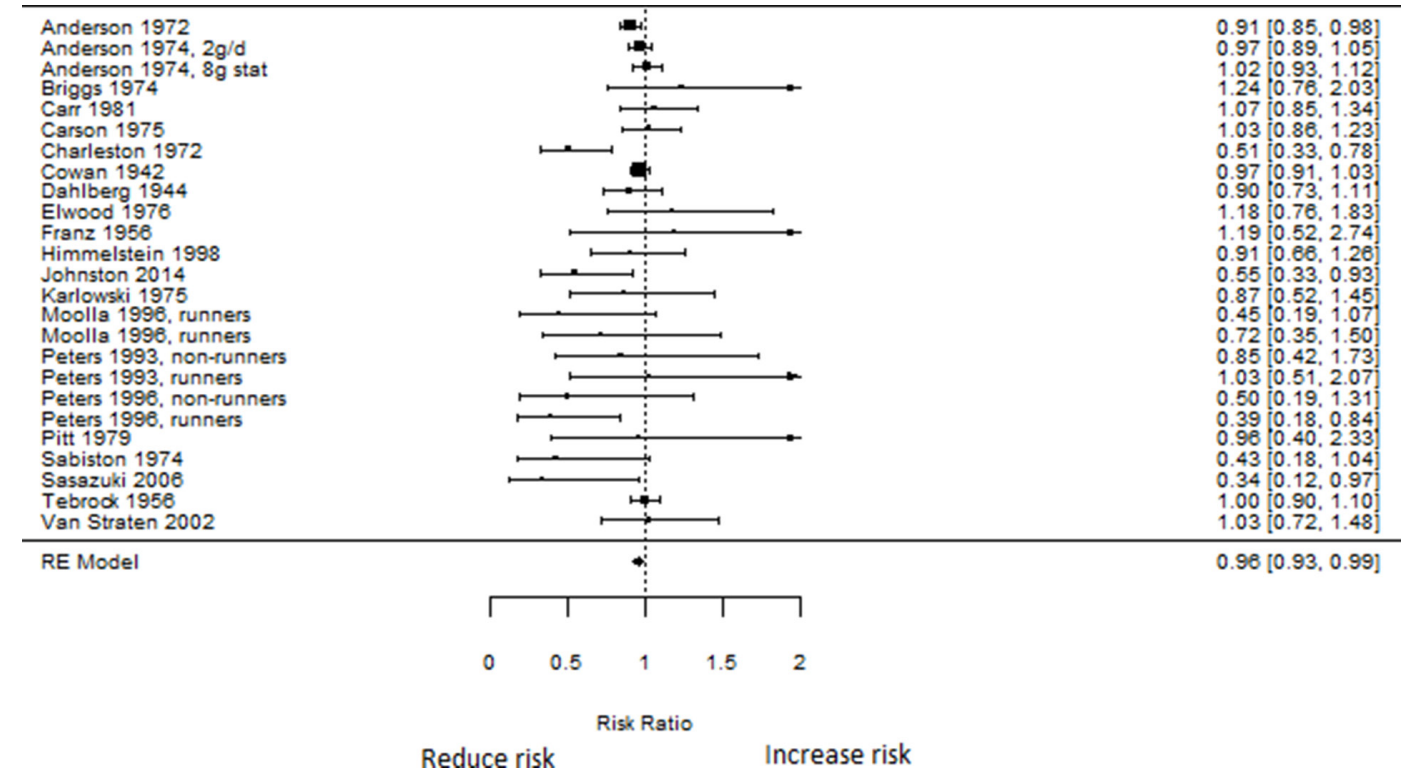

Figure 4 Vitamin $\mathrm{C}$ and the risk of acute respiratory tract infection (ARI) among adults. RE, Random effects. 


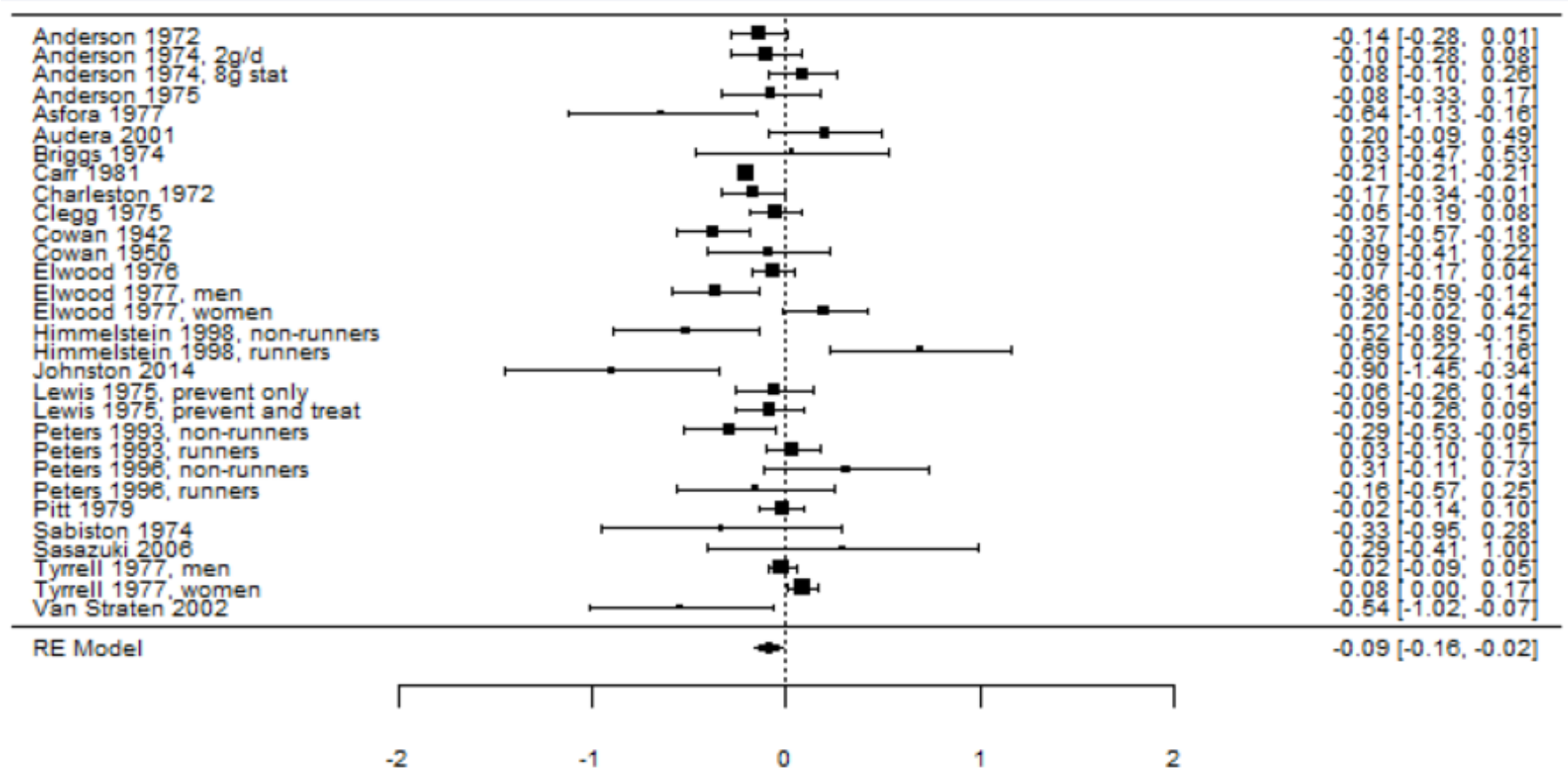

Log Ratio of Means

Reduce duration

Increase duration

Figure 5 Vitamin $\mathrm{C}$ to reduce the duration of acute respiratory tract infection (ARI) symptoms. RE, Random effects.

the duration of common cold symptoms was $-9 \%(95 \%$ CI $-16 \%$ to $-3 \%$; $\mathrm{p}=0.007)$. There was substantial heterogeneity in the estimates $\left(\mathrm{I}^{2}=65 \%\right)$ and no evidence of publication bias on inspection of the funnel plots (online supplemental figure 10). None of the individual studies had significant influence on the magnitude or direction of the pooled estimates.

\section{Zinc supplementation}

Occurrence of illness

Five studies examined the effect of zinc supplementation on prevention of common cold among 554 adults (online supplemental table 5) ${ }^{81-85}$ One study had a low risk of bias, ${ }^{84}$ while the risk of bias of the other four studies was high. ${ }^{81-8385}$ Three experimental challenge studies in the UK and USA inoculated healthy volunteers with rhinovirus types 2, 23 or 39 and evaluated whether or not

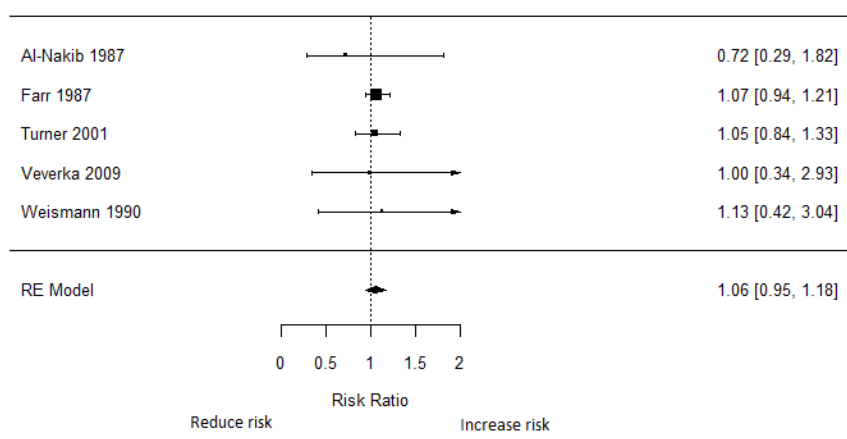

Figure 6 Zinc supplementation for reducing the risk of acute respiratory tract infection (ARI). RE, Random effects. infection occurred based on detecting rhinovirus in viral cell culture. ${ }^{81-83}$ Two of these had additional antibody testing. ${ }^{82}{ }^{83}$ Zinc had no effect on the risk of infection in all three studies, though their sample sizes were small $(\mathrm{n}=\leq 91) .{ }^{81-83}$ Zinc supplementation had no effect on the risk of common cold among 145 adults in Denmark or clinical URTI among 40 US air force cadets. ${ }^{84}$

The pooled RR of zinc on the prevention of ARI (common cold and other ARIs) was 1.06 (95\% CI 0.95 to $1.18 ; \mathrm{p}=0.31$; figure 6 ). There was no evidence of heterogeneity $\left(\mathrm{I}^{2}=0 \%\right)$ and no evidence of publication bias (online supplemental figure 11). The pooled RR did not change on restricting to the four studies of zinc on common cold (RR: 1.06 ; $95 \%$ CI 0.95 to 1.18 ; $\mathrm{p}=0.31$ ). The pooled RR was neither influenced by the magnitude of the daily dose, nor by sex, geographical location (continent) or study duration.

\section{Duration of symptoms}

Nine studies examined the effect of zinc supplementation on shortening the duration of common cold among 1038 adults, and all nine reported significant effects. ${ }^{86-94}$ There was a low risk of bias for one study, ${ }^{91}$ with some concern for four studies ${ }^{87889394}$ and high for four studies. ${ }^{86} 899092$ These studies were conducted in Australia ${ }^{95}$ and the USA. ${ }^{86-94}$ In an experimental challenge study, zinc (13 mg every 2 hours) shortened the duration of symptoms from 3.5 days to 2.5 days, relative to placebo, among 91 volunteers. ${ }^{89}$

In terms of dose, most studies provided $23 \mathrm{mg}$ of zinc $^{82869096}$ or $13 \mathrm{mg}^{8892-94}$ every two to three wakeful 
hours. Among 99 adults in the USA, zinc supplementation significantly reduced the time to resolution of all symptoms (median reduction of 4.4 days compared with 7.6 days in the placebo group; $\mathrm{p}<0.001) .{ }^{88}$ The zinc group had significantly fewer days with most symptomscoughing, headache, hoarseness, nasal congestion and sore throat-but did not differ in the number of fever days. Among 65 US adults, zinc supplementation was associated with a shorter duration of symptoms ${ }^{86}$ Half of the participants were asymptomatic in 2.7 days in the zinc group and in 7.5 days in the placebo group. After 7 days, $86 \%$ in the zinc group were asymptomatic, compared with only $46 \%$ in the placebo group.

A few studies provided zinc in the form of nasal gels. ${ }^{8791}$ For instance, among 213 US adults, the duration of symptoms was $2.3( \pm 0.9)$ days in the zinc group but $9.0( \pm 2.5)$ days in the placebo group. ${ }^{87}$ Among 80 US adults with recent onset of symptoms, nasal zinc supplementation reduced the duration of symptoms from 6 days to 4.3 days.

Two additional studies examined the effect of zinc supplementation on shortening the duration of symptoms of other ARIs. In the first, members of 34 families in Australia were randomly assigned to $10 \mathrm{mg}$ of zinc acetate or placebo four or more times daily on developing respiratory symptoms. ${ }^{95}$ Zinc supplementation had no impact on the duration of symptoms of URTI. In the second study, zinc supplementation led to a $13 \%$ reduction in the proportion of individuals with symptoms of URTI among 174 volunteers in the USA. ${ }^{96}$ Most of the participants in this study were students.

The pooled percentage difference for the effect of zinc supplementation on the duration of symptoms from 11 studies of common cold and other ARIs (figure 7) was $-47 \%$ (95\% CI $-73 \%$ to $-21 \% ; \mathrm{p}=0.0004)$. There was considerable heterogeneity in the estimates $\left(\mathrm{I}^{2}=94 \%\right)$. The funnel plot was asymmetrical, (online supplemental figure 12), suggesting possible publication bias. Trimand-fill analysis suggests three studies may be missing on the left side, and the corrected pooled percentage difference would be $-63 \%$ (95\% CI $-90 \%$ to $-36 \%)$. The pooled percentage difference was significantly different

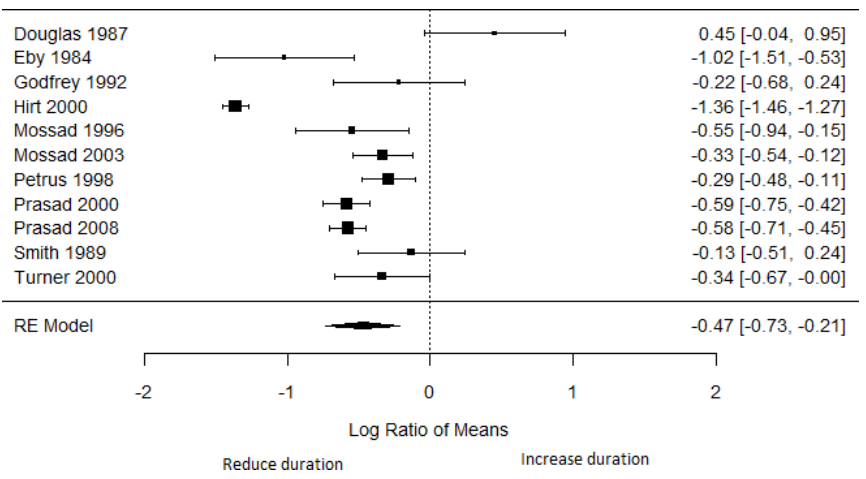

Figure 7 Zinc supplementation to shorten the duration of acute respiratory tract infection (ARI) symptoms. RE, Random effects. in the Australian study compared with the US studies $(\mathrm{p}=0.023)$. Dose of elemental zinc ( $>13.3 \mathrm{mg}$ vs $\leq 13.3 \mathrm{mg}$; $\mathrm{p}=0.39$ ) and the type of zinc compound (acetate vs gluconate) did not influence the pooled estimate $(p=0.41)$. The pooled percentage difference was influenced neither by the magnitude of the daily dose and sex, nor by study duration.

The pooled percentage difference for the effect of zinc supplementation on the duration of common cold symptoms from nine studies (online supplemental figure 13) was $-59 \%(95 \%$ CI $-84 \%$ to $-35 \%$; $\mathrm{p}<0.0001)$. There was considerable heterogeneity in the estimates $\left(\mathrm{I}^{2}=93 \%\right)$, but no evidence of publication bias (online supplemental figure 14).

\section{Multiple micronutrient supplementation}

\section{Occurrence of illness}

Seven studies examined the effect of supplementation with combinations of micronutrients on ARI occurrence (online supplemental table 6) among 4510 adults. ${ }^{5497-102}$ There was a low risk of bias for two studies, ${ }^{97} 102$ with some concerns for three studies ${ }^{5498100}$ and high for two studies. ${ }^{99} 101$ Three studies among older adults ( $>50$ years) in India, ${ }^{98}$ the USA $^{102}$ and the Netherlands ${ }^{101}$ provided MMS at the local recommended dietary allowances (RDAs) for each micronutrient and found no significant ARI-preventive effects. While the studies in India and the USA had small sample sizes, $n=36$ and $n=61$, respectively, the study in the Netherlands included 652 participants. There were small and statistically insignificant effects of MMS at $50 \%$ of local RDAs among 2799 older adults in Chile ${ }^{99}$ or a combination of vitamins $\mathrm{B}, \mathrm{C}$ and $\mathrm{E}$ at the local RDAs among 725 nursing home residents in France. ${ }^{100}$

Studies among adults $\leq 50$ years in South Africa and Mexico found MMS to reduce the risk of ARIs by $21 \%$ and $40 \%$, respectively. These studies were short-term, with follow-up lasting 1-3 months. The first study was conducted among 178 ultramarathoners in South Africa, provided with a daily supplement containing $30000 \mathrm{IU}$ of vitamin A, $400 \mathrm{IU}$ of vitamin $\mathrm{E}$ and $500 \mathrm{mg}$ of vitamin C for 21 days prior to a marathon and 2 weeks postrace. The second was conducted among 59 individuals susceptible to ARI in Mexico, provided with supplementation for 90 days. ${ }^{97}$ The dose was at least twofold US RDAs for some nutrients (cobalamin, biotin and manganese), onefold to twofold RDAs for some nutrients (vitamins A, $\mathrm{B}, \mathrm{C}$ and zinc) and below RDAs for others (vitamin D, calcium, selenium and copper).

Taken together, studies of MMS used diverse formulations making pooling and any inferences impossible.

\section{Duration of symptoms}

Among 36 individuals aged 51-78 years in India who received MMS at RDA level, MMS was associated with a twofold shorter overall duration of ARI symptoms. ${ }^{98}$ In addition, antibiotics were also used for fewer days in the MMS group. No other studies examined the impact of MMS on duration of symptoms. 


\section{Other micronutrients}

Seven studies examined the effects of vitamin $\mathrm{A}$ and vitamin $\mathrm{E}$, but could not be pooled (online supplemental table 7 ). There was a low risk of bias for one study, ${ }^{103}$ with some concerns for two studies ${ }^{54}$ and high for the others. ${ }^{101104105}$ Three of these examined the effect of vitamin A supplementation to prevent ARIs. One of these was in older adults. Among 29133 smokers in a cancer prevention trial in Finland, vitamin A supplementation had no impact on the risk of hospital-treated pneumonia over 6 years of follow-up. ${ }^{103}$ The other two studies were conducted in younger populations of marathoners in South Africa (<50 years). Both $4.5 \mathrm{mg} /$ day and $18 \mathrm{mg} /$ day reduced the risk of URTI considerably $(23 \%$ and $9 \%$, respectively), though the CIs were wide. Vitamin A also reduced the risk of URTI by $16 \%$ in age-matched nonrunners. ${ }^{55}$ Taken together, the effect of vitamin A on ARI risk appears to differ by age.

Four studies examined the effects of vitamin $\mathrm{E}$ on the risk of ARI. ${ }^{101103105106}$ Among 617 elderly residents of 33 long-term care facilities in Massachusetts, USA, vitamin E supplementation was associated with a $17 \%$ lower risk of colds $(\mathrm{RR}=0.83 ; 95 \%$ CI 0.68 to 1.01$)$, but had no influence on the risk of other ARIs or the duration of symptoms for either colds or other ARIs. ${ }^{104}$ Among 652 community-dwelling older adults in the Netherlands, vitamin E supplementation had no effect on the risk or duration of symptoms of ARIs during 2 years of follow-up. ${ }^{101}$

Two of the four studies were conducted in a cohort of male smokers in a cancer prevention trial in Finland. Vitamin E (50 mg/day) had no significant effect on the risk of hospital-treated pneumonia in the overall population of 29133 individuals. However, vitamin E supplementation led to $69 \%$ and $72 \%$ lower rates of ARI among smokers who commenced smoking after 21 years of age, ${ }^{103}$ and among heavy smokers with $\geq 20$ cigarettes/ day. ${ }^{105}$ Vitamin $\mathrm{E}$ had no effect on the duration of symptoms in the overall population.

\section{DISCUSSION}

We reviewed 80 RCTs that examined the effects of micronutrients on the occurrence and course of ARIs among adults. Vitamin D, vitamin C and MMS reduced the risk of ARIs by $3 \%-21 \%$. Vitamin D, vitamin $\mathrm{C}$ and zinc shortened the duration of ARI symptoms by $6 \%-59 \%$. Here we explore these results and identify gaps in published studies.

Our findings indicate that vitamin D supplementation reduces ARI risk by $3 \%$ overall, and by $18 \%$ when ARI was diagnosed based on laboratory testing or clinical diagnosis. This is comparable to findings in previous meta-analyses. ${ }^{7-11}$ The current study focuses on adults and includes recent trials. ${ }^{3641}$ Vitamin D levels are insufficient in $\geq 50 \%$ of the global population, even though moderate sun exposure should be enough to prevent it. ${ }^{107}$ Vitamin D modulates immunity through effects on macrophage, dendritic and $\mathrm{T}$ cell function. ${ }^{108}$ Vitamin
D promotes T-helper 2 (Th2) response and suppresses T-helper 1 (Th1) cells by enhancing interleukin (IL)-4, IL-5 and IL-10 production. ${ }^{109110}$ In addition, many pathogens provoke oxidative stress and vitamin $\mathrm{D}$ enhances the production of antioxidative enzymes that counter it. ${ }^{108}$ Notably, the trials were conducted in temperate, highincome countries, limiting the generalisability of our findings to this setting. Further, the studies did not always report baseline levels of vitamin D and any adverse events of supplementation.

Vitamin C was observed to have a modest effect of preventing ARIs and shortening the duration of ARI symptoms. This is consistent with evidence from previously published meta-analyses. ${ }^{12}{ }^{13}$ Vitamin $\mathrm{C}$ is an important cofactor for enzymes involved in tissue repair after an insult or injury. ${ }^{111}$ Vitamin $\mathrm{C}$ also has critical antioxidant properties, thereby limiting inflammation and improving recovery. ${ }^{112}$ This effect is stronger in people with vitamin $\mathrm{C}$ deficiency, as well as those undergoing stressful conditions. ${ }^{113}$ Though frank vitamin C deficiency or scurvy is rare, recent studies have shown the potential for adverse consequences in persons with subnormal vitamin $\mathrm{C}$ levels. ${ }^{114}$ Notably, the effect of vitamin $\mathrm{C}$ to prevent ARIs was considerably stronger in middle-income countries, compared with high-income ones. There was no significant dose-response relationship of vitamin $\mathrm{C}$ with the risk of ARI or duration of symptoms, and included studies did not evaluate the adverse events due to vitamin $\mathrm{C}$.

Evidence from the current and previous meta-analyses demonstrate that zinc supplementation shortens the duration of ARIs considerably. ${ }^{15} 17$ In addition, zinc supplementation prevents mortality related to severe pneumonia. ${ }^{18}$ Zinc deficiency is widespread, affecting almost $20 \%$ of the global population, and regular intake of adequate quantities of zinc is required to prevent it. ${ }^{115}$ Zinc is a component of hundreds of enzymes and transcription factors, and plays critical roles in gene expression, cell division and immunity. ${ }^{116}$ It regulates the proliferation, differentiation, maturation, and functioning of epithelial cells and leucocytes. ${ }^{117}$ It also modulates the production of $\mathrm{T}$ lymphocytes, cytokines and reactive oxygen species. ${ }^{117118}$ In addition, zinc improves appetite and its deficiency leads to anorexia, impairing intake of macronutrients and micronutrients essential to mount a robust immune response. ${ }^{117}$

Multiple micronutrient deficiencies have been previously associated with elevated risk of respiratory infections, especially among the elderly. ${ }^{119}$ The studies included in this review used diverse formulations, and any inferences regarding the preventive effect of MMS was not possible. MMS, however, shortened the duration of symptoms considerably in the one study among older adults in India that examined it. ${ }^{98}$ It is plausible that the absence of an observed effect on prevention could be related to the dose of the micronutrients, or the extent of dietary inadequacies and nutritional deficiencies in the study population. Micronutrients are often provided at or below RDA level, which could be inadequate to 
address existing deficiencies. Evidence from studies of the effect of supplement administration on other viral infections such as HIV also support the potential that MMS could significantly slow disease progression and reduce mortality among HIV-infected individuals. ${ }^{120} 121$

It is possible that supplementation with vitamin C, zinc and vitamin D, possibly as part of MMS, may prevent SARS-CoV-2 infection and shorten the duration of COVID-19 symptoms. No primary studies have examined the impact of these micronutrients on the risk of SARS-CoV-2 infection. One study that examined the influence of vitamin $\mathrm{C}$ on any coronaviruses had only a few cases, and found no significant effect. ${ }^{34}$ In addition to their general effects as modulators of immunity discussed above, both vitamin $\mathrm{D}$ and zinc have antiviral effects, including through induction of cathelicidin to disrupt viral envelopes or by combining with pyrithione to inhibit RNA polymerase activity. ${ }^{122} 123$ Vitamin D also acts on cellular and genetic pathways that regulate clotting, and may ameliorate COVID-induced coagulation, especially among those with vitamin D deficiency. ${ }^{124}$ There is preliminary evidence that lower vitamin D levels are present in patients with COVID-19 in comparison to hospital controls, and that the extent of COVID-19 mortality is proportional to the national severity of vitamin $\mathrm{D}$ deficiency. ${ }^{125}$ This evidence is however ecological, and any significant relationships could be due to intractable confounding or systematic differences in assessment of exposure or outcome. Further, the impact of individual or combination micronutrient supplements to shorten the duration of viral respiratory illnesses may be particularly critical to free up healthcare resources, especially bed space in intensive care units and in the general hospital wards. Individuals with the most severe nutritional deficiencies are observed to receive greater benefits from supplementation, ${ }^{10} 113$ strengthening the ethical imperative to evaluate utility of different supplements in treating and preventing COVID-19. RCTs of these micronutrients among patients with COVID-19 are therefore warranted, particularly during the current stage of the pandemic which provides a unique window to enrol large study populations. These studies should carefully consider differential effects among individuals who may be replete or deficient for the relevant micronutrient, as well as the potential role for supraphysiological amounts.

Determining whether to recommend supplementation and the relevant dose is critical for clinical and public health planning, especially in the context of the ongoing response to COVID-19. We examined the effect of different dose categories on the preventive and treatment effects of the micronutrients evaluated in this meta-analysis. Notably, we found that while vitamin $\mathrm{D}$ was $3 \%$ protective in the general population, it was $10 \%$ protective if the daily dose was $\geq 2000$ IU. We found that providing a monthly or loading dose was beneficial if it was $<60000 \mathrm{IU}$, but not if it was $\geq 60000 \mathrm{IU}-$ possibly because large doses could disrupt enzyme metabolism of vitamin D. ${ }^{126}$ We also find that weekly dosing (10 $000 \mathrm{IU}$ or $20000 \mathrm{IU}$ ) was $30 \%$ protective. Using multiplepredictor meta-regression, we identify the best dosing regimen provided a loading dose is $>0$ IU to $<60000 \mathrm{IU}$, and a daily dose is $\geq 2000$ IU for prevention of infection. We found no differential effect of dose of vitamin $\mathrm{D}$ when used as treatment, and it is plausible that a high loading dose may be warranted particularly among deficient individuals so as to rapidly correct vitamin D status during the narrow window of illness, followed by lower daily maintenance doses. The effects of vitamin $\mathrm{C}$ and zinc supplementation were not modified by the dose of supplement provided.

Our review was limited by the availability and nature of primary studies. Most of the studies were conducted in high-income countries, limiting generalisability of our findings to those settings. Many studies classified the outcomes of interest based on self-report, resulting in error which could have reduced our power to identify significant associations. Many of the included studies had high risk of bias or some concerns-partly due to a dependence on self-report for outcome assessment. In addition, there were no studies conducted among pregnant women. Furthermore, it was impractical to examine the impact of micronutrients on the severity of symptoms due to the substantially different ways that severity was assessed in the studies, and this may have contributed to heterogeneity in pooled analyses. Studies used different assays to estimate baseline micronutrient status, due to changes in laboratory standards and techniques over time. There were no significant dose-response relationships for many of the exposure-outcome relationships assessed. Adverse event information was limited, and we are therefore unable to assess the safety of supraphysiological doses. Finally, minimum clinically important differences have not been established for these outcomes, and we are unable to conclude whether these findings are clinically meaningful. Given the mix of the quality or randomised trials reviewed and the sources of bias in the primary studies, we conclude that the evidence presented likely reflects the true effect of the micronutrients on the risk of ARIs, and strength of evidence is moderate. Further research may change some of our conclusions.

\section{CONCLUSION}

Our synthesis of global evidence from RCTs indicates that micronutrient supplements including zinc, vitamins $\mathrm{C}$ and $\mathrm{D}$, and multiple micronutrient supplements may be modestly effective in preventing ARIs and improving their clinical course. Further research is warranted to better understand the effectiveness that individual or multiple micronutrients have on SARS-CoV-2 infection and treatment outcomes.

\section{Twitter Ajibola Ibraheem Abioye @drabioye}

Contributors The paper was drafted by AIA, SB and WF. WF designed the study. AIA reviewed titles, abstracts and full texts, and extracted data as necessary. All authors contributed to the development of and approved the final version of the manuscript. The authors have full access to all of the data in the study and take responsibility for the integrity of the review.

Funding The authors have not declared a specific grant for this research from any funding agency in the public, commercial or not-for-profit sectors.

Competing interests None declared.

Patient consent for publication Not required. 
Provenance and peer review Not commissioned; externally peer reviewed.

Data availability statement All data relevant to the study are included in the article or uploaded as supplementary information and are available via medical literature databases.

Supplemental material This content has been supplied by the author(s). It has not been vetted by BMJ Publishing Group Limited (BMJ) and may not have been peer-reviewed. Any opinions or recommendations discussed are solely those of the author(s) and are not endorsed by BMJ. BMJ disclaims all liability and responsibility arising from any reliance placed on the content. Where the content includes any translated material, BMJ does not warrant the accuracy and reliability of the translations (including but not limited to local regulations, clinical guidelines terminology, drug names and drug dosages), and is not responsible for any error and/or omissions arising from translation and adaptation or otherwise.

Open access This is an open access article distributed in accordance with the Creative Commons Attribution Non Commercial (CC BY-NC 4.0) license, which permits others to distribute, remix, adapt, build upon this work non-commercially, and license their derivative works on different terms, provided the original work is properly cited, appropriate credit is given, any changes made indicated, and the use is non-commercial. See: http://creativecommons.org/licenses/by-nc/4.0/.

\section{ORCID iD}

Ajibola Ibraheem Abioye http://orcid.org/0000-0002-6632-613X

\section{REFERENCES}

1 Ritchie H, Roser M. Causes of Death. In: Our world in data, 2018

2 World Health Organization (WHO). Influenza (seasonal) Geneva, Switzerland: World Health organization, 2020. Available: https:// www.who.int/news-room/fact-sheets/detail/influenza-(seasonal [Accessed 3 May 2020]

3 Astuti I, Ysrafil. Severe acute respiratory syndrome coronavirus 2 (SARS-CoV-2): an overview of viral structure and host response. Diabetes Metab Syndr 2020;14:407-12.

4 Ludvigsson JF. Systematic review of COVID-19 in children shows milder cases and a better prognosis than adults. Acta Paediatr 2020;109:1088-95.

5 Wu Z, McGoogan JM. Characteristics of and important lessons from the coronavirus disease 2019 (COVID-19) outbreak in China: summary of a report of 72314 cases from the Chinese center for disease control and prevention. JAMA 2020;323:1239-42.

6 Calder PC, Carr AC, Gombart AF, et al. Optimal nutritional status for a well-functioning immune system is an important factor to protect against viral infections. Nutrients 2020;12:1181.

7 Bergman P, Lindh AU, Björkhem-Bergman L, et al. Vitamin D and respiratory tract infections: a systematic review and meta-analysis of randomized controlled trials. PLoS One 2013;8:e65835.

8 Vuichard Gysin D, Dao D, Gysin CM, et al. Effect of vitamin D3 supplementation on respiratory tract infections in healthy individuals: a systematic review and meta-analysis of randomized controlled trials. PLoS One 2016;11:e0162996.

9 Mao S, Huang S. Vitamin D supplementation and risk of respiratory tract infections: a meta-analysis of randomized controlled trials. Scand J Infect Dis 2013;45:696-702.

10 Martineau AR, Jolliffe DA, Greenberg L, et al. Vitamin D supplementation to prevent acute respiratory infections: individual participant data meta-analysis. Health Technol Assess 2019;23:1-44.

11 Charan J, Goyal JP, Saxena D, et al. Vitamin D for prevention of respiratory tract infections: a systematic review and meta-analysis. J Pharmacol Pharmacother 2012;3:300-3.

12 Hemilä $\mathrm{H}$, Chalker E. Vitamin C for preventing and treating the common cold. Cochrane Database Syst Rev 2013:Cd000980.

13 Ran L, Zhao W, Wang J, et al. Extra dose of vitamin C based on a daily supplementation shortens the common cold: a meta-analysis of 9 randomized controlled trials. Biomed Res Int 2018;2018:1-12.

14 Hemilä H, Louhiala P. Vitamin C for preventing and treating pneumonia. Cochrane Database Syst Rev 2013:CD005532.

15 D'Cruze H, Arroll B, Kenealy T. Is intranasal zinc effective and safe for the common cold? A systematic review and meta-analysis. $J$ Prim Health Care 2009;1:134-9.

16 Jackson JL, Peterson C, Lesho E. A meta-analysis of zinc salts lozenges and the common cold. Arch Intern Med 1997;157:2373-6.

17 Science M, Johnstone J, Roth DE, et al. Zinc for the treatment of the common cold: a systematic review and meta-analysis of randomized controlled trials. CMAJ 2012;184:E551-61.
18 Wang L, Song Y. Efficacy of zinc given as an adjunct to the treatment of severe pneumonia: a meta-analysis of randomized, double-blind and placebo-controlled trials. Clin Respir J 2018:12:857-64.

19 Hodinka RL. Respiratory RNA viruses. Microbiol Spectr 2016;4.

20 Stevenson M, Stevenson MM, BiasedUrn I. Package 'epiR', 2020.

21 Sterne JAC, Savović J, Page MJ, et al. Rob 2: a revised tool for assessing risk of bias in randomised trials. BMJ 2019;366:14898.

22 Hedges LV, Gurevitch J, Curtis PS. The meta-analysis of response ratios in experimental ecology. Ecology 1999;80:1150-6.

23 Hemilä $\mathrm{H}$, Chalker E. Meta-Analysis on vitamin $\mathrm{C}$ and the common cold in children may be misleading. Eur J Clin Pharmacol 2019;75:1747-8.

24 Hemilä $\mathrm{H}$, Chalker E. Vitamin $\mathrm{C}$ for preventing and treating the common cold. Cochrane Database Syst Rev 2013:Cd000980.

25 Higgins JPT, Altman DG, Gøtzsche PC, et al. The Cochrane collaboration's tool for assessing risk of bias in randomised trials. BMJ 2011;343:d5928.

26 Viechtbauer W, Viechtbauer MW. Package 'metafor'. the comprehensive R archive network package 'metafor', 2015. Available: http://cran r-project org/web/packages/metafor/metafor pdf

27 RStudio Team. RStudio: integrated development for R. Boston, MA: RStudio, Inc, 2015: 42. 14. http://www rstudio com

28 Simpson S, van der Mei I, Stewart N, et al. Weekly cholecalciferol supplementation results in significant reductions in infection risk among the vitamin D deficient: results from the CIPRIS pilot RCT. BMC Nutr 2015:1:7.

29 Goodall EC, Granados AC, Luinstra K, et al. Vitamin D3 and gargling for the prevention of upper respiratory tract infections: a randomized controlled trial. BMC Infect Dis 2014:14:273

30 Laaksi I, Ruohola J-P, Mattila V, et al. Vitamin D supplementation for the prevention of acute respiratory tract infection: a randomized, double-blinded trial among young Finnish men. $J$ Infect Dis 2010;202:809-14.

31 Arihiro S, Nakashima A, Matsuoka M, et al. Randomized trial of vitamin D supplementation to prevent seasonal influenza and upper respiratory infection in patients with inflammatory bowel disease. Inflamm Bowel Dis 2019;25:1088-95.

32 Shimizu Y, Ito Y, Yui K, et al. Intake of 25-hydroxyvitamin D3 reduces duration and severity of upper respiratory tract infection: a randomized, double-blind, placebo-controlled, parallel group comparison study. J Nutr Health Aging 2018;22:491-500.

33 de Gruijl FR, Pavel S. The effects of a mid-winter 8-week course of sub-sunburn sunbed exposures on tanning, vitamin $D$ status and colds. Photochem Photobiol Sci 2012;11:1848-54.

34 Murdoch DR, Slow S, Chambers ST, et al. Effect of vitamin D3 supplementation on upper respiratory tract infections in healthy adults: the VIDARIS randomized controlled trial. JAMA 2012;308:1333-9.

35 Slow S, Epton M, Storer M, et al. Effect of adjunctive single highdose vitamin $\mathrm{D}_{3}$ on outcome of community-acquired pneumonia in hospitalised adults: The VIDCAPS randomised controlled trial. Sci Rep 2018:8:13829.

36 Camargo CA, Sluyter J, Stewart AW, et al. Effect of monthly highdose vitamin $D$ supplementation on acute respiratory infections in older adults: a randomized controlled trial. Clin Infect Dis 2020;71:311-7.

37 Bergman P, Norlin A-C, Hansen S, et al. Vitamin D supplementation to patients with frequent respiratory tract infections: a post hoc analysis of a randomized and placebo-controlled trial. BMC Res Notes 2015;8:391.

38 Martineau AR, Hanifa Y, Witt KD, et al. Double-Blind randomised controlled trial of vitamin D3 supplementation for the prevention of acute respiratory infection in older adults and their carers (ViDiFlu). Thorax 2015;70:953-60.

39 Martineau AR, James WY, Hooper RL, et al. Vitamin D3 supplementation in patients with chronic obstructive pulmonary disease (ViDiCO): a multicentre, double-blind, randomised controlled trial. Lancet Respir Med 2015;3:120-30.

40 Martineau AR, MacLaughlin BD, Hooper RL, et al. Double-Blind randomised placebo-controlled trial of bolus-dose vitamin D3 supplementation in adults with asthma (ViDiAs). Thorax 2015;70:451-7

41 Aloia JF, Islam S, Mikhail M. Vitamin D and acute respiratory Infections-The PODA trial. Open Forum Infect Dis 2019;6:ofz228.

42 Aloia JF, Li-Ng M. Re: epidemic influenza and vitamin D. Epidemiol Infect 2007;135:1095-6.

43 Denlinger LC, King TS, Cardet JC, et al. Vitamin D supplementation and the risk of colds in patients with asthma. Am J Respir Crit Care Med 2016;193:634-41. 
44 Ginde AA, Blatchford P, Breese K, et al. High-Dose monthly vitamin $D$ for prevention of acute respiratory infection in older long-term care residents: a randomized clinical trial. J Am Geriatr Soc 2017;65:496-503.

$45 \mathrm{Li}-\mathrm{Ng} \mathrm{M}$, Aloia JF, Pollack S, et al. A randomized controlled trial of vitamin D3 supplementation for the prevention of symptomatic upper respiratory tract infections. Epidemiol Infect 2009;137:1396-404.

46 Rees JR, Hendricks K, Barry EL, et al. Vitamin D3 supplementation and upper respiratory tract infections in a randomized, controlled trial. Clin Infect Dis 2013;57:1384-92.

47 Tran B, Armstrong BK, Ebeling PR, et al. Effect of vitamin D supplementation on antibiotic use: a randomized controlled trial. Am J Clin Nutr 2014;99:156-61.

48 Briggs $\mathrm{MH}$. Letter: clinical trials with vitamin C. Lancet 1974;2:1211-2.

49 Carr AB, Einstein R, Lai LY, et al. Vitamin C and the common cold: a second MZ Cotwin control study. Acta Genet Med Gemellol 1981;30:249-55.

50 Anderson TW, Suranyi G, Beaton GH. The effect on winter illness of large doses of vitamin C. Can Med Assoc J 1974;111:31-6.

51 Anderson TW, Reid DB, Beaton GH. Vitamin C and the common cold: a double-blind trial. Can Med Assoc J 1972;107:503-8.

52 Sasazuki S, Sasaki S, Tsubono Y, et al. Effect of vitamin C on common cold: randomized controlled trial. Eur J Clin Nutr 2006;60:9-17.

53 Peters EM, Goetzsche JM, Grobbelaar B, et al. Vitamin C supplementation reduces the incidence of postrace symptoms of upper-respiratory-tract infection in ultramarathon runners. $A m \mathrm{~J}$ Clin Nutr 1993;57:170-4.

54 Peters E, Goetzsche J, Joseph L. Vitamin C as effective as combinations of anti-oxidant nutrients in reducing symptoms of upper respiratory tract infection in ultramarathon runners. $S$ Afr J Sports Med 1996;11:23-7.

55 Moolla ME. The role of anti-oxidants in the prevention of post-race upper respiratory tract infection. University of Cape Town, 1997.

56 Dahlberg $\mathrm{G}$, Engel A, Rydin $\mathrm{H}$. The value of ascorbic acid as a prophylactic against »common colds».1. Acta Med Scand 1944;119:540-61.

57 Carson M, Cox H, CORBETT M, et al. Vitamin $\mathrm{C}$ and the common cold. Occup Med 1975;25:99-102.

58 Clegg KM, Macdonald JM. L-Ascorbic acid and D-isoascorbic acid in a common cold survey. Am J Clin Nutr 1975;28:973-6.

59 Elwood PC, Lee HP, St Leger AS, et al. A randomized controlled trial of vitamin $C$ in the prevention and amelioration of the common cold. Br J Prev Soc Med 1976;30:193-6.

60 Elwood PC, Hughes SJ, Leger AS. A randomized controlled trial of the therapeutic effect of vitamin $\mathrm{C}$ in the common cold. Practitioner 1977;218:133-7.

61 Cowan DW, Diehl HS, Baker AB. Vitamins for the prevention of colds. J Am Med Assoc 1942;120:1268-71.

62 Karlowski TR, Chalmers TC, Frenkel LD, et al. Ascorbic acid for the common cold. A prophylactic and therapeutic trial. JAMA 1975;231:1038-42

63 Pitt HA, Costrini AM. Vitamin C prophylaxis in marine recruits. JAMA 1979;241:908-11.

64 Himmelstein SA, Robergs RA, Koehler KM. Vitamin C supplementation and upper respiratory tract infections in marathon runners. J Exerc Physiol 1998;1.

65 Johnston CS, Barkyoumb GM, Schumacher SS. Vitamin C supplementation slightly improves physical activity levels and reduces cold incidence in men with marginal vitamin $C$ status: a randomized controlled trial. Nutrients 2014;6:2572-83.

66 Sabiston B, Radomski M. Health problems and vitamin C in Canadian Northern military operations. In: Defence and civil Institute of environmental medicine report no 74-R-M2, 1974.

67 Charleston S, Clegg KM. Ascorbic acid and the common cold. Lancet 1972;299:1401-2.

68 Brown WB, Mahoney F, Niedringhaus A. Weather and susceptibility in relation to the spread of common cold; effect of ascorbic acid, in massive dosage, on duration. J Immunol 1945;50:161-77.

69 Franz WL, Heyl HL, Sands GW. Blood ascorbic acid level in bioflavonoid and ascorbic acid therapy of common cold. J Am Med Assoc 1956;162:1224-6.

70 Tebrock HE, Arminio JJ, Johnston JH. Usefulness of bioflavonoids and ascorbic acid in treatment of common cold. J Am Med Assoc 1956;162:1227-33.

71 Schwartz AR, Togo Y, Hornick RB, et al. Evaluation of the efficacy of ascorbic acid in prophylaxis of induced rhinovirus 44 infection in man. J Infect Dis 1973;128:500-5.
72 Audera C, Patulny RV, Sander BH, et al. Mega-dose vitamin C in treatment of the common cold: a randomised controlled trial. Med $J$ Aust 2001;175:359-62.

73 Anderson TW, Beaton GH, Corey P, et al. Winter illness and vitamin C: the effect of relatively low doses. Can Med Assoc J 1975;112:823-6.

74 Abott P, Abrahams M, Adams MSM. Ineffectiveness of vitamin C in treating coryza. Practitioner 1968;200:442-5.

75 Van Straten M, Josling P. Preventing the common cold with a vitamin C supplement: a double-blind, placebo-controlled survey. Adv Ther 2002;19:151-9.

76 Tyrrell DA, Craig JW, Meada TW, et al. A trial of ascorbic acid in the treatment of the common cold. Br J Prev Soc Med 1977;31:189-91.

77 Regnier E. The administration of large doses of ascorbic acid in the prevention and treatment of the common cold. II. Rev Allergy 1968;22:948-56.

78 Cowan DW, Diehl HS. Antihistaminic agents and ascorbic acid in the early treatment of the common cold. J Am Med Assoc 1950;143:421-4.

79 Lewis TL, Karlowski TR, Kapikian AZ, et al. A controlled clinical trial of ascorbic acid for the common cold. Ann N Y Acad Sci 1975;258:505-12.

80 Asfora J. Vitamin C in high doses in the treatment of the common cold. Int J Vitam Nutr Res1977;16:219-34.

81 Al-Nakib W, Higgins PG, Barrow I, et al. Prophylaxis and treatment of rhinovirus colds with zinc gluconate lozenges. J Antimicrob Chemother 1987;20:893-901.

82 Farr BM, Conner EM, Betts RF, et al. Two randomized controlled trials of zinc gluconate lozenge therapy of experimentally induced rhinovirus colds. Antimicrob Agents Chemother 1987;31:1183-7.

83 Turner RB. Ineffectiveness of intranasal zinc gluconate for prevention of experimental rhinovirus colds. Clin Infect Dis 2001;33:1865-70.

84 Veverka DV, Wilson C, Martinez MA, et al. Use of zinc supplements to reduce upper respiratory infections in United States air force Academy cadets. Complement Ther Clin Pract 2009;15:91-5.

85 Weismann K, Jakobsen JP, Weismann JE, et al. Zinc gluconate lozenges for common cold. A double-blind clinical trial. Dan Med Bull 1990;37:279-81.

86 Eby GA, Davis DR, Halcomb WW. Reduction in duration of common colds by zinc gluconate lozenges in a double-blind study. Antimicrob Agents Chemother 1984;25:20-4.

87 Hirt M, Nobel S, Barron E. Zinc nasal gel for the treatment of common cold symptoms: a double-blind, placebo-controlled trial. Ear Nose Throat J 2000;79:778-82.

88 Mossad SB, Macknin ML, Medendorp SV, et al. Zinc gluconate lozenges for treating the common cold. A randomized, doubleblind, placebo-controlled study. Ann Intern Med 1996;125:81-8.

89 Turner RB, Cetnarowski WE. Effect of treatment with zinc gluconate or zinc acetate on experimental and natural colds. Clin Infect Dis 2000;31:1202-8.

90 Godfrey JC, Conant Sloane B, Smith DS, et al. Zinc gluconate and the common cold: a controlled clinical study. J Int Med Res 1992;20:234-46.

91 Mossad SB. Effect of zincum gluconicum nasal gel on the duration and symptom severity of the common cold in otherwise healthy adults. QJM 2003;96:35-43.

92 Petrus EJ, Lawson KA, Bucci LR, et al. Randomized, doublemasked, placebo-controlled clinical study of the effectiveness of zinc acetate lozenges on common cold symptoms in allergy-tested subjects. Curr Ther Res Clin Exp 1998;59:595-607.

93 Prasad AS, Fitzgerald JT, Bao B, et al. Duration of symptoms and plasma cytokine levels in patients with the common cold treated with zinc acetate. A randomized, double-blind, placebo-controlled trial. Ann Intern Med 2000;133:245-52.

94 Prasad AS, Beck FWJ, Bao B, et al. Duration and severity of symptoms and levels of plasma interleukin-1 receptor antagonist, soluble tumor necrosis factor receptor, and adhesion molecules in patients with common cold treated with zinc acetate. J Infect Dis 2008;197:795-802.

95 Douglas RM, Miles HB, Moore BW, et al. Failure of effervescent zinc acetate lozenges to alter the course of upper respiratory tract infections in Australian adults. Antimicrob Agents Chemother $1987 ; 31: 1263-5$.

96 Smith DS, Helzner EC, Nuttall CE, et al. Failure of zinc gluconate in treatment of acute upper respiratory tract infections. Antimicrob Agents Chemother 1989;33:646-8.

97 Bernal-Orozco MF, Posada-Falomir M, Ortega-Orozco R, et al. Effects of a dietary supplement on the incidence of acute 
respiratory infections in susceptible adults: a randomized controlled trial. Nutr Hosp 2015;32:722-31.

98 Jain AL. Influence of vitamins and trace-elements on the incidence of respiratory infection in the elderly. Nutr Res 2002;22:85-7.

99 Dangour AD, Albala C, Allen E, et al. Effect of a nutrition supplement and physical activity program on pneumonia and walking capacity in Chilean older people: a factorial cluster randomized trial. PLoS Med 2011;8:e1001023.

100 Girodon F, Galan P, Monget AL, et al. Impact of trace elements and vitamin supplementation on immunity and infections in institutionalized elderly patients: a randomized controlled trial. min. Vit. AOX. geriatric network. Arch Intern Med 1999;159:748-54.

101 Graat JM, Schouten EG, Kok FJ. Effect of daily vitamin E and Multivitamin-Mineral supplementation on acute respiratory tract infections in elderly persons. JAMA 2002;288:715-21.

102 Johnson MA, Porter KH. Micronutrient supplementation and infection in institutionalized elders. Nutr Rev 1997;55:400-4.

103 Hemilä H, Virtamo J, Albanes D, et al. Vitamin E and beta-carotene supplementation and hospital-treated pneumonia incidence in male smokers. Chest 2004;125:557-65.

104 Meydani SN, Leka LS, Fine BC, et al. Vitamin E and respiratory tract infections in elderly nursing home residents: a randomized controlled trial. JAMA 2004;292:828-36.

105 Hemilä $\mathrm{H}$. Vitamin $\mathrm{E}$ administration may decrease the incidence of pneumonia in elderly males. Clin Interv Aging 2016;11:1379-85.

106 Meydani SN, Han SN, Hamer DH. Vitamin E and respiratory infection in the elderly. Ann N Y Acad Sci 2004;1031:214-22.

107 van Schoor N, Lips P. Global overview of vitamin D status. Endocrinol Metab Clin North Am 2017;46:845-70.

108 Lei G-S, Zhang C, Cheng B-H, et al. Mechanisms of action of vitamin $D$ as supplemental therapy for Pneumocystis pneumonia. Antimicrob Agents Chemother 2017;61. doi:10.1128/AAC.0122617. [Epub ahead of print: 22 Sept 2017].

109 Lemire JM, Archer DC, Beck L, et al. Immunosuppressive actions of 1,25-dihydroxyvitamin D3: preferential inhibition of Th1 functions. $J$ Nutr 1995;125:1704S--08S.

110 Boonstra A, Barrat FJ, Crain C, et al. 1alpha,25-Dihydroxyvitamin d3 has a direct effect on naive CD4(+) T cells to enhance the development of Th2 cells. J Immunol 2001;167:4974-80.

111 Padayatty SJ, Levine M. Vitamin C: the known and the unknown and Goldilocks. Oral Dis 2016;22:463-93.

112 Hemilä H. Vitamin C, respiratory infections and the immune system. Trends Immunol 2003;24:579-80.
113 Hemilä H. Vitamin C and infections. Nutrients 2017;9. doi:10.3390/ nu9040339. [Epub ahead of print: 29 Mar 2017].

114 Borrelli E, Roux-Lombard P, Grau GE, et al. Plasma concentrations of cytokines, their soluble receptors, and antioxidant vitamins can predict the development of multiple organ failure in patients at risk. Crit Care Med 1996;24:392-7.

115 Wessells KR, Brown KH. Estimating the global prevalence of zinc deficiency: results based on zinc availability in national food supplies and the prevalence of stunting. PLoS One 2012;7:e50568.

116 Read SA, Obeid S, Ahlenstiel C, et al. The role of zinc in antiviral immunity. Adv Nutr 2019;10:696-710.

117 Tanumihardjo SA, Russell RM, Stephensen CB, et al. Biomarkers of nutrition for development (BOND)-Vitamin A review. J Nutr 2016;146:1816S-48.

118 Prasad AS. Zinc: role in immunity, oxidative stress and chronic inflammation. Curr Opin Clin Nutr Metab Care 2009;12:646-52.

119 Hamer DH, Sempértegui F, Estrella B, et al. Micronutrient deficiencies are associated with impaired immune response and higher burden of respiratory infections in elderly Ecuadorians. $J$ Nutr 2009;139:113-9.

120 Fawzi WW, Msamanga GI, Spiegelman D, et al. A randomized trial of multivitamin supplements and HIV disease progression and mortality. N Engl J Med 2004;351:23-32.

121 Sudfeld CR, Buchanan A, Ulenga N, et al. Effectiveness of a multivitamin supplementation program among HIV-infected adults in Tanzania. AIDS 2019;33:93-100.

122 Grant WB, Lahore H, McDonnell SL, et al. Evidence that vitamin D supplementation could reduce risk of influenza and COVID-19 infections and deaths. Nutrients 2020;12:988.

123 Zhang L, Liu Y. Potential interventions for novel coronavirus in China: a systematic review. J Med Virol 2020;92:479-90.

124 Mohammad S, Mishra A, Ashraf MZ. Emerging role of vitamin D and its associated molecules in pathways related to pathogenesis of thrombosis. Biomolecules 2019;9:649.

125 Daneshkhah A, Agrawal V, Eshein A. The possible role of vitamin $D$ in suppressing cytokine storm and associated mortality in COVID-19 patients. medRxiv 2020 doi:10.1101/2020.04.08.20058578

126 Vieth R. How to optimize vitamin D supplementation to prevent cancer, based on cellular adaptation and hydroxylase enzymology. Anticancer Res 2009;29:3675-84. 